\title{
When is Discretion Superior to Timeless Perspective Policymaking?
}

\author{
Richard Dennis \\ Federal Reserve Bank of San Francisco
}

January 2010

Working Paper 2008-21

http://www.frbsf.org/publications/economics/papers/2008/wp08-21bk.pdf

The views in this paper are solely the responsibility of the authors and should not be interpreted as reflecting the views of the Federal Reserve Bank of San Francisco or the Board of Governors of the Federal Reserve System. 


\title{
When is Discretion Superior to Timeless Perspective Policymaking?*
}

\author{
Richard Dennis ${ }^{\dagger}$ \\ Federal Reserve Bank of San Francisco
}

January 2010

\begin{abstract}
The monetary policy literature assumes increasingly that policies are formulated according to the timeless perspective (Woodford, 1999a). However, treating the auxiliary state variables that characterize the timeless perspective equilibrium appropriately when evaluating policy performance, this paper shows that discretionary policymaking can be superior to timeless perspective policymaking and identifies model features that make this outcome more likely. Using standard New Keynesian DSGE models, discretion is found to dominate timeless perspective policymaking when the price/wage Phillips curves are relatively flat, due, perhaps, to firm-specific capital (or labor) and/or Kimball (1995) aggregation in combination with nominal rigidities. These results suggest that studies applying the timeless perspective might also usefully compare its performance to discretion, paying careful attention to how policy performance is evaluated.
\end{abstract}

Keywords: Discretion, timeless perspective, policy evaluation.

JEL Classification: C61, E52, E58.

${ }^{*}$ I would like to thank Jinill Kim, Stephen Sauer, Andrea Tambalotti, and participants at the Norges Bank Workshop on Optimal Monetary Policy, 2008, for comments. The views expressed in this paper do not necessarily reflect those of the Federal Reserve Bank of San Francisco or the Federal Reserve System.

${ }^{\dagger}$ Address for Correspondence: Economic Research, Mail Stop 1130, Federal Reserve Bank of San Francisco, 101 Market St, CA 94105, USA. Email: richard.dennis@sf.frb.org. 


\section{Introduction}

Much work in recent decades has been devoted to understanding how central banks should conduct monetary policy. It is now generally accepted that private sector expectations can be an important channel through which monetary policy operates and that the time-consistency issues raised by Kydland and Prescott (1977) are a legitimate and material policy concern. These concerns feature prominently in the monetary policy design literature, which emphasizes the distinction between commitment and discretion, and are taken seriously by central banks, many of whom have adopted inflation targeting policy regimes. Although optimal commitment policies (Kydland and Prescott, 1980) have the obvious attraction of being optimal, they are unattractive in so much as their performance is attributable to a central bank that exploits private-sector expectations in some arbitrary initial period while promising never to do so again. Because discretionary policies are known to be suboptimal and optimal commitment policies are not time-consistent and depend on arbitrary initial conditions, Woodford and coauthors have argued that monetary policy might better be conducted according to a "timeless perspective".

The timeless perspective approach to policy design was first outlined in Woodford (1999a), advanced as a solution to the "initial period" problem that characterizes optimal commitment policies. ${ }^{1}$ At that time, Woodford (1999a) argued that the initial period problem could be overcome if the central bank were to "adopt, not the pattern of behavior from now on that would be optimal to choose, taking expectations as given, but rather the pattern of behavior to which it would have wished to commit itself to at a date far in the past, contingent upon the random events that have occurred in the meantime." Simply put, the initial period problem ceases to be a problem once the initial period has long since passed. In subsequent work, the concepts of timeless perspective policymaking and timeless perspective equilibria have been refined and made more formal. ${ }^{2}$ Because the timeless perspective overcomes the initial period problem, the literature on monetary policy has embraced it, to the point where such policies increasingly form the backbone of policy analysis, and one central bank-Norges Bank-has employed the timeless perspective to construct its public interest rate forecasts.

Timeless perspective policies are closely related to optimal commitment policies. In par-

\footnotetext{
${ }^{1}$ Related to the timeless perspective, King and Wolman (1999) and Khan, King, and Wolman (2003) analyze responses to exogenous shocks once the economy has reached its stationary distribution under the optimal commitment policy. Unlike the timeless perspective, however, they do not propose to overwrite the optimal commitment policy when analyzing transitional dynamics.

${ }^{2}$ See Woodford (2003), Giannoni and Woodford (2002a,b), and Benigno and Woodford (2003, 2006).
} 
ticular, both policies involve auxiliary state variables that track the value of commitments over time. One implication of these auxiliary state variables is that timeless perspective policies involve commitments and are not time-consistent in the sense of Kydland and Prescott (1977). At the same time, timeless perspective policies are not optimal in the sense of Kydland and Prescott (1980), opening the door to the possibility that they may be inferior to other suboptimal policies, such as discretion.

In this paper I ask whether discretionary monetary policy can dominate policy designed according to the timeless perspective and answer in the affirmative. The paper then examines the factors that govern this result, employing a microfounded dynamic stochastic general equilibrium (DSGE) model to ascertain the role that nominal and real rigidities play in determining whether discretion is superior. Indeed, it is shown that discretion is more likely to dominate timeless perspective policymaking in models where nominal and real rigidities are important. Two additional contributions of the paper are that it develops a measure of policy performance suitable for consistently evaluating timeless perspective and discretionary policies and that it shows how timeless perspective equilibria can be obtained from the solution to an unmodified formulation of the optimal commitment problem (c.f. Woodford (2003)). It is important to compare the performance of timeless perspective policies to discretion because such a comparison helps to identify and understand situations where timeless perspective policymaking may be inferior to discretion. More generally, such a comparison allows us to better understand when discretionary policies perform well and when timeless perspective policies perform less well.

Previous studies that compare discretion to timeless perspective policymaking have tended to focus on unconditional loss when evaluating policy performance ${ }^{3}$ (McCallum and Nelson, 2004; Sauer, 2007). However, there are several good reasons not to use unconditional loss for this purpose. One reason is that the loss function common to both the timeless perspective and discretionary optimization problems is (invariably) conditional. Another reason is that using unconditional loss to evaluate performance amounts to comparing discretion to the optimal commitment policy because the timeless perspective policy and the optimal commitment policy share the same asymptotic equilibrium. A third reason is that, by ignoring transition dynamics, the use of unconditional loss can generate spurious performance reversals

\footnotetext{
${ }^{3}$ Indeed, some have interpreted the term "timeless perspective" to mean that timeless perspective policies should be derived as the solution to an unconditional optimization problem (Blake, 2001, Jensen and McCallum, 2002, Damjanovic, Damjanovic, and Nolan, 2008). Since Woodford's approach to timeless perspective policy design does not do this, these studies have found that timeless perspective policies are not optimal from the timeless perspective.
} 
(Kim, Kim, Schaumburg, and Sims, 2008). Rather than use unconditional loss to compare the two policy strategies, a measure of conditional loss is developed that is suitable for the task. Specifically, the paper shows how the auxiliary state variables that enter the timeless perspective equilibrium can be "integrated out" to produce a measure of conditional loss that is invariant to the multiplicity that is known to characterize timeless perspective policymaking (Woodford, 2003, chapter 7), that remains conditional on the natural state variables common to both the decision problems, and that does not ignore transition dynamics. For linearquadratic models, this integration lowers the performance of the timeless perspective policy relative to the optimal commitment policy by terms that quantify the conditional mean and the conditional volatility of the auxiliary states.

Of course, it is far from automatic that these adjustments will permit a timeless perspective to be dominated by discretion. However, using standard New Keynesian DSGE models, it is shown that factors that flatten the New Keynesian Phillips curve, such as nominal price rigidity, firm-specific labor/capital, and Kimball (1995) aggregation, can raise the conditional volatility (in particular) of the auxiliary state variables to the point where discretion becomes the superior policy. Indeed, the intuition for this result is reasonably clear. As the Phillips curve becomes increasingly flat, the central bank must generate greater volatility in real marginal costs in order to stabilize inflation. To the extent that real marginal costs are correlated with the central bank's other policy objectives, this volatility in real marginal costs raises the volatility of the commitments that characterize the timeless perspective policy, penalizing its performance.

The remainder of this paper is organized as follows. Section 2 introduces the timeless perspective approach to policy design, applying it to a simple New Keynesian model. Section 2 also shows why the treatment of the auxiliary states in the loss function matters importantly for performance comparisons. Section 3 illustrates how standard control methods for rational expectations models can be used to construct and analyze the equilibrium of a timeless perspective policy. In addition, Section 3 shows how the auxiliary state variables can be conditionally integrated out to construct a measure of policy performance that is easy to compute and that is suitable for comparing the performance of discretion and timeless perspective policies. Applying this measure of policy performance to the simple New Keynesian model introduced in Section 2, Section 4 demonstrates that discretion can be superior to timeless perspective policymaking. Extending the analysis to a small-scale DSGE model, Section 4 also shows that factors that flatten the slopes of the wage and price Phillips curves increase 
the likelihood that discretion will be superior to timeless perspective policymaking. Section 5 concludes.

\section{Timeless perspective policymaking: design and performance}

In this section a simple new Keynesian model is used to derive the optimal commitment policy as well as targeting rules for policy under the timeless perspective and discretion, respectively. With these policies in hand, the section considers two standard methods for assessing policy performance and shows that neither performance measure is entirely satisfactory.

\subsection{A simple example}

Consider the following decision problem. The central bank seeks to choose the sequence of nominal interest rates $\left\{i_{t}\right\}_{0}^{\infty}$ to minimize the loss function

$$
L_{0}=\mathrm{E}_{0} \sum_{t=0}^{\infty} \beta^{t}\left(\pi_{t}^{2}+\mu y_{t}^{2}+\nu i_{t}^{2}\right),
$$

where $\pi_{t}$ represents inflation, $y_{t}$ represents the output gap, $\beta \in(0,1)$ denotes the subjective discount factor, $\mu \in[0, \infty)$ and $\nu \in[0, \infty)$ denote the weights on output and interest rate stabilization relative to inflation stabilization, respectively, and $\mathrm{E}_{0}$ is the mathematical expectations operator conditional on period 0 information. Under certain circumstances, equation (1) can be viewed as a second-order accurate approximation to household welfare (Benigno and Woodford, 2006). For the purposes of this section, however, equation (1) is taken to be primal.

Constraining the central bank's decision problem is the system

$$
\begin{aligned}
\pi_{t} & =\beta \mathrm{E}_{t} \pi_{t+1}+\kappa y_{t}+u_{t}, \\
y_{t} & =\mathrm{E}_{t} y_{t+1}-\sigma\left(i_{t}-\mathrm{E}_{t} \pi_{t+1}\right)+r_{t}^{n}, \\
u_{t+1} & =\rho_{u} u_{t}+\epsilon_{u t+1}, \\
r_{t+1}^{n} & =\rho_{r} r_{t}^{n}+\epsilon_{r t+1}
\end{aligned}
$$

where $u_{t}$ represents a markup shock, $r_{t}^{n}$ represents a neutral-rate shock, and the initial conditions $u_{0}$ and $r_{0}^{n}$ are known. The innovations $\epsilon_{u t}$ and $\epsilon_{r t}$ are assumed to be i.i.d. with zero mean and finite variance. Equation (2) is the New Keynesian Phillips curve obtained from a Calvo-pricing model (Calvo, 1983). Equation (3) is the standard consumption-Euler equation that, because the model abstracts from government spending, investment, and trade, is 
written in terms of the output gap. Equations (4) and (5) describe the laws of motion for the markup shock and the neutral-rate shock. The parameters $\{\kappa, \sigma\} \in(0, \infty)$ denote the price rigidity and the elasticity of intertemporal substitution, respectively, while $\left\{\rho_{u}, \rho_{r}\right\} \in(-1,1)$ summarize the persistence properties of the two shocks.

\subsection{Optimal commitment policy}

The optimal commitment policy can be found by choosing $\left\{\pi_{t}, y_{t}, i_{t}\right\}_{0}^{\infty}$ to minimize equation (1) subject to equations (2) through (5). In addition to equations (2) through (5), the firstorder conditions for this decision problem are

$$
\begin{aligned}
\beta \pi_{t}+\lambda_{\pi t+1} & =0, \quad t=0, \\
\mu \beta y_{t}-\kappa \lambda_{\pi t+1}+\beta \lambda_{y t+1} & =0, \quad t=0, \\
\beta \pi_{t}+\lambda_{\pi t+1}-\lambda_{\pi t}-\sigma \lambda_{y t} & =0, \quad t>0, \\
\mu \beta y_{t}-\kappa \lambda_{\pi t+1}+\beta \lambda_{y t+1}-\lambda_{y t} & =0, \quad t>0, \\
\nu i_{t}+\sigma \lambda_{y t+1} & =0, \quad t \geq 0,
\end{aligned}
$$

where $\lambda_{\pi t+1}$ and $\lambda_{y t+1}$ are the Lagrange multipliers associated with equations (2) and (3), respectively.

The time inconsistency of the optimal commitment policy is reflected in the difference's between equations (6) through (7) and equations (8) through (9), which imply a different policy when $t=0$ than when $t>0$. Notice, however, that these differences disappear when $\lambda_{\pi 0}=\lambda_{y 0}=0$. As a consequence, the optimal commitment policy can be obtained by applying standard saddle-point solution methods to equations (2) through (5) and (8) through (10), with the initial conditions $\lambda_{\pi 0}=\lambda_{y 0}=0$ and $u_{0}, r_{0}^{n}$, known.

\subsection{Timeless perspective policy}

To obtain a Woodford (1999a) timeless perspective policy for this model we employ equations (6) through (10) as follows. First, to introduce the timeless perspective, assume that equations (8) and (9) also apply when $t=0$, effectively discarding equations (6) and (7). Then, to obtain a policy that is implementable, use equation (10) to solve for $\lambda_{y t+1}$ and equation (9) to solve for $\lambda_{\pi t+1}$ and substitute these expressions into equation (8) to eliminate the two Lagrange multipliers. With these substitutions, the resulting timeless perspective policy is

$$
\pi_{t}+\frac{\mu}{\kappa}\left(y_{t}-y_{t-1}\right)-\frac{\nu}{\sigma \kappa \beta}\left[(\beta+\sigma \kappa)\left(i_{t}-i_{t-1}\right)-\left(i_{t-1}-i_{t-2}\right)\right]+\frac{\nu}{\beta} i_{t}=0, \quad t \geq 0 .
$$


Provided $\nu>0$, equation (11) can be solved for $i_{t}$, giving rise to what is known as an explicit targeting rule. The timeless perspective equilibrium is now obtained by solving for the rational expectations equilibrium of equations (2) through (5) and (11), with $u_{0}, i_{-1}$, and $i_{-2}$ known. Notice that in this model the timeless perspective policy depends on the change in the output gap, a point emphasized by Walsh (2003) in his discussion of "speed limit" policies, and on lags of the interest rate, a point Woodford (1999b) highlights in his analysis of optimal interest rate inertia. Further, reflecting the general property stressed by Giannoni and Woodford (2002b), because the shocks are not directly present, timeless perspective targeting rules, such as equation (11), are robust to misspecification of the shock processes.

\subsection{Discretion policy}

The targeting rule characterizing discretion can be obtained in straightforward fashion using a variation on the method introduced by Cohen and Michel (1988). Because the only state variables in the model are the shocks, $u_{t}$ and $r_{t}^{n}$, it must be the case that $\mathrm{E}_{t} \pi_{t+1}=\theta_{\pi u} \rho_{u} u_{t}+$ $\theta_{\pi r} \rho_{r} r_{t}^{n}$ and $\mathrm{E}_{t} y_{t+1}=\theta_{y u} \rho_{u} u_{t}+\theta_{y r} \rho_{r} r_{t}^{n}$, in any (Markov) time-consistent equilibrium, where the coefficients $\theta_{\pi u}, \theta_{\pi r}, \theta_{y u}$, and $\theta_{y r}$ have yet to be determined. The discretionary control problem is then to choose $\left\{\pi_{t}, y_{t}, i_{t}\right\}_{0}^{\infty}$ to minimize the Lagrangean

$$
\begin{aligned}
\mathcal{L}_{0}= & \mathrm{E}_{0} \sum_{t=0}^{\infty} \beta^{t}\left[\left(\pi_{t}^{2}+\mu y_{t}^{2}+\nu i_{t}^{2}\right)\right. \\
& +2 \lambda_{\pi t+1}\left(\pi_{t}-\beta\left(\theta_{\pi u} \rho_{u} u_{t}+\theta_{\pi r} \rho_{r} r_{t}^{n}\right)-\kappa y_{t}-u_{t}\right) \\
& \left.+2 \lambda_{y t}\left(y_{t}-\left(\theta_{y u} \rho_{u} u_{t}+\theta_{y r} \rho_{r} r_{t}^{n}\right)+\sigma\left(i_{t}-\theta_{\pi u} \rho_{u} u_{t}+\theta_{\pi r} \rho_{r} r_{t}^{n}-r_{t}^{n}\right)\right)\right] .
\end{aligned}
$$

Differentiating equation (12) with respect to $\pi_{t}, y_{t}$, and $i_{t}$ produces the first-order conditions

$$
\begin{aligned}
\pi_{t}+\lambda_{\pi t+1} & =0, \quad t \geq 0 \\
\mu y_{t}-\kappa \lambda_{\pi t+1}+\lambda_{y t+1} & =0, \quad t \geq 0 \\
\nu i_{t}+\sigma \lambda_{y t+1} & =0, \quad t \geq 0
\end{aligned}
$$

which lead directly to the targeting rule

$$
\pi_{t}+\frac{\mu}{\kappa} y_{t}-\frac{\nu}{\sigma \kappa} i_{t}=0, \quad t \geq 0
$$

The (Markov) time-consistent equilibrium is then found by solving the rational expectations system described by equations (2) through (5) and (16), yielding values for $\theta_{\pi u}, \theta_{\pi r}, \theta_{y u}$, and $\theta_{y r} \cdot{ }^{4}$

\footnotetext{
${ }^{4}$ Beause this model does not contain any endogenous state variables, there is no need to iterate over $\theta_{\pi u}$, $\theta_{\pi r}, \theta_{y u}$, and $\theta_{y r}$ to obtain a fix-point.
} 


\subsection{Policy performance}

To compare the performance of the timeless perspective policy to those of the optimal commitment policy and the discretion policy we need a method for evaluating the performance of the timeless perspective policy, an exercise that is complicated by the presence of the auxiliary state variables, $y_{t-1}, i_{t-1}$, and $i_{t-2}$ in the timeless perspective targeting rule. Here, two standard methods for evaluating policy performance are considered. ${ }^{5}$ The first method is to evaluate loss conditional on the entire initial state vector, including the auxiliary states. The second method is to evaluate performance using unconditional loss. With the simple New Keynesian model serving to illustrate, it is shown that neither of these methods is entirely satisfactory.

Simplifying, in the special case that $\nu=0$, equations (11) and (16) collapse to

$$
\begin{aligned}
\pi_{t}+\frac{\mu}{\kappa}\left(y_{t}-y_{t-1}\right) & =0, \quad t \geq 0, \\
\pi_{t}+\frac{\mu}{\kappa} y_{t} & =0, \quad t \geq 0,
\end{aligned}
$$

respectively. It follows that the state is described by $u_{t}$ for the discretion policy, by $u_{t}$ and $\lambda_{\pi t}$ for the optimal commitment policy, and by $u_{t}$ and $y_{t-1}$ for the timeless perspective policy. As is now illustrated numerically, ${ }^{6}$ the performances associated with each of these policies depends importantly on how these differences among the state variables is treated.

\section{[ Figure 1 here ]}

The first method of assessing policy performance is to simply evaluate equation (1) conditional on the relevant initial states. For the optimal commitment policy and the discretion policy, it is straightforward to evaluate equation (1), since both policies assume a given known value for $u_{0}$ and since for the optimal commitment policy it is known that $\lambda_{\pi 0}=0$. It is slightly more complicated for the timeless perspective policy, since that policy requires an initial value for $y_{-1}$, the lagged output gap. Consider Figure 1A, which displays $(1-\beta) L_{0}$, where $L_{0}$ is given by equation (1), for $u_{0}=0$ and for an array of different initial values for the lagged output gap. By construction, the optimal commitment policy generates the best performance, with the optimal commitment policy delivering a 4.3 percent improvement in performance over discretion. Also by construction, because $y_{-1}$ is not a state variable in either the discretionary equilibrium or the optimal commitment equilibrium, the performances associated with these policies are invariant to this auxiliary state variable.

\footnotetext{
${ }^{5}$ Sauer (2007) provides a related discussion.

${ }^{6}$ The model is parameterized by setting $\kappa=0.025, \rho_{u}=0.20, \beta=0.99, \sigma_{\epsilon_{u}}=1$, and $\mu=0.50$.
} 
Now consider the performances associated with the timeless perspective policy. For the timeless perspective, performance is maximized when $y_{-1}=0$ and rises symmetrically for absolute deviations in $y_{-1}$ about 0 . In fact, when $y_{-1}=0$, the timeless perspective policy performs identically to the optimal commitment policy. Most obviously, Figure 1A reveals that as $y_{-1}$ becomes larger in magnitude, loss for the timeless perspective policy increases to become larger than the loss for discretion. Clearly there exist states (here a lagged output gap greater than about 0.5 percent) for which discretion is superior, delivering a better performance-from period-0 onward - than the timeless perspective policy. This is an issue for a central bank pursuing a timeless perspective policy because in states where discretion is superior it is not clear that the central bank would continue to implement the inferior policy, highlighting the time inconsistency of the timeless perspective policy. Timeless perspective policies perform poorly when the output gap is large because the timeless perspective assumes that it is the stationary asymptotic equilibrium - and not initial expectations or transition dynamics - that governs outcomes.

With policies evaluated according to equation (1), it is not difficult to see that it will always be possible to find states where discretion is superior to timeless perspective policymaking for any model in which there is a time-consistency problem. ${ }^{7}$ An alternative to evaluating policy according to equation (1), hinted at in the discussion above, is to use unconditional loss. By using the unconditional expectation of equation (1), the timeless perspective policy's dependence on the initial state is eliminated in the performance calculation. Figure 1B displays unconditional loss for each policy, where the initial state has been integrated out using the (unconditional) probability density implied by the model. ${ }^{8}$ Since policies are now being evaluated according to the characteristics of their asymptotic equilibrium, and the optimal commitment policy and the timeless perspective policy share the same asymptotic equilibrium, these policies deliver the same unconditional loss. Clearly, if unconditional loss is used to measure performance, then discretion is the inferior policy.

However, although it is common to use unconditional loss when assessing timeless perspective policy performance, there are good reasons for not doing so. Aside from the most obvious point, which is that the discretionary problem, the optimal commitment problem, and

\footnotetext{
${ }^{7}$ To the extent that timeless perspective commitments are untenable in such states, this consideration provides motivation for the "quasi-commitment" equilibrium analyzed by Schaumburg and Tambalotti (2007) and the "loose commitment" equilibrium studied by Debartoli and Nunes (2006).

${ }^{8}$ Importantly, to the extent that observed data are not well explained by the model, very different results might be obtained if the integration used the observed frequency distribution for the state variables rather than using the model-implied density function.
} 
the timeless perspective problem are all explicitly conditioned on an observed known initial state, it is well known that ignoring transition dynamics and evaluating policies according to their asymptotic behavior can lead to spurious welfare reversals (Kim, Kim, Schaumburg, and Sims, 2008).

Figure 1A shows that discretion can be superior to timeless perspective policymaking, however neither equation (1) nor its unconditional expectation seems entirely satisfactory for quantifying timeless perspective policy performance: the former depends on auxiliary state variables, here $y_{-1}$, while the latter ignores initial conditions and transition dynamics. The following section analyzes timeless perspective policymaking in the general linear-quadratic framework and develops a measure of policy performance that is better suited to evaluating timeless perspective policies and to comparing their performance to discretion.

\section{The general LQ framework}

This section analyzes policy design in the general LQ framework and makes two main contributions. First, it presents a simple method for obtaining a timeless perspective equilibrium. Importantly, the solution method advanced below requires neither modifying the policy objective function nor introducing initial-period optimization constraints (c.f. Giannoni and Woodford (2002a, 2009), Woodford (2003, chapter 7), and Benigno and Woodford (2006)). Instead, the solution method engineers a timeless perspective equilibrium from the solution to the optimal commitment problem. In addition, the multiplicity known to characterize timeless perspective policymaking (Woodford, 1999a; Woodford, 2003, chapter 7) is discussed and illustrated.

Second, the section develops a metric to evaluate policy performance that is invariant to this multiplicity and that can be applied consistently to timeless perspective policies and discretionary policies. To obtain this performance metric, the approach is to integrate the conditional loss function with respect to the auxiliary state variables that are introduced by the timeless perspective policy commitment. The result is a measure of policy performance that is invariant to the multiplicity that characterizes timeless perspective policymaking, that remains conditional on the natural state variables common to both discretion and the timeless perspective, and that does not ignore transition dynamics. 


\subsection{The commitment solution}

Let the economic environment be one in which an $n \times 1$ vector of endogenous variables, $\mathbf{z}_{t}$, consisting of $n_{1}$ predetermined variables, $\mathbf{x}_{t}$, and $n_{2}\left(n_{2}=n-n_{1}\right)$ nonpredetermined variables, $\mathbf{y}_{t}$, evolves over time according to

$$
\begin{aligned}
\mathbf{x}_{t+1} & =\mathbf{A}_{\mathbf{x x}} \mathbf{x}_{t}+\mathbf{A}_{\mathbf{x y}} \mathbf{y}_{t}+\mathbf{B}_{\mathbf{x u}} \mathbf{u}_{t}+\varepsilon_{t+1}, \\
\mathrm{E}_{t} \mathbf{y}_{t+1} & =\mathbf{A}_{\mathbf{y x}} \mathbf{x}_{t}+\mathbf{A}_{\mathbf{y y}} \mathbf{y}_{t}+\mathbf{B}_{\mathbf{y u}} \mathbf{u}_{t},
\end{aligned}
$$

where $\mathbf{u}_{t}$ is a $p \times 1$ vector of policy control variables, $\boldsymbol{\varepsilon}_{t} \sim$ i.i.d. $[\mathbf{0}, \boldsymbol{\Sigma}]$ is an $s \times 1\left(s \leq n_{1}\right)$ vector of white-noise innovations, and $\mathrm{E}_{t}$ is the private sector's mathematical expectations operator conditional upon period $t$ information. The matrices $\mathbf{A}_{\mathbf{x x}}, \mathbf{A}_{\mathbf{x y}}, \mathbf{A}_{\mathbf{y x}}, \mathbf{A}_{\mathbf{y y}}, \mathbf{B}_{\mathbf{x u}}$, and $\mathbf{B}_{\mathbf{y u}}$ contain the structural parameters that govern preferences and technology and are conformable with $\mathbf{x}_{t}, \mathbf{y}_{t}$, and $\mathbf{u}_{t}$ as necessary. The matrix $\mathbf{A}_{\mathbf{y y}}$ is assumed to have full rank.

Subject to equations (19) and (20) and $\mathbf{x}_{0}$ known, the control problem is for the policymaker to choose the sequence of control variables $\left\{\mathbf{u}_{t}\right\}_{0}^{\infty}$ to minimize

$$
\mathrm{E}_{0} \sum_{t=0}^{\infty} \beta^{t}\left(\mathbf{z}_{t}^{\prime} \mathbf{W} \mathbf{z}_{t}+2 \mathbf{z}_{t}^{\prime} \mathbf{U} \mathbf{u}_{t}+\mathbf{u}_{t}^{\prime} \mathbf{R} \mathbf{u}_{t}\right)
$$

where $\mathbf{z}_{t} \equiv\left[\begin{array}{cc}\mathbf{x}_{t}^{\prime} & \mathbf{y}_{t}^{\prime}\end{array}\right]^{\prime}$. Methods to solve this optimal commitment problem are by now well known (Oudiz and Sachs (1985), Backus and Driffill (1986), Currie and Levine (1993), Söderlind (1999)). For the purposes of this section, however, what is important is that the commitment equilibrium has the form

$$
\begin{aligned}
\mathbf{x}_{t+1} & =\mathbf{M}_{\mathbf{x x}} \mathbf{x}_{t}+\mathbf{M}_{\mathbf{x p}} \mathbf{p}_{t}+\varepsilon_{t+1}, \\
\mathbf{p}_{t+1} & =\mathbf{M}_{\mathbf{p x}} \mathbf{x}_{t}+\mathbf{M}_{\mathbf{p p}} \mathbf{p}_{t}, \\
\mathbf{d}_{t} & =\mathbf{G}_{\mathbf{d x}} \mathbf{x}_{t}+\mathbf{G}_{\mathbf{d p}} \mathbf{p}_{t},
\end{aligned}
$$

where $\mathbf{d}_{t} \equiv\left[\begin{array}{c}\mathbf{y}_{t} \\ \mathbf{u}_{t}\end{array}\right]$ and $\mathbf{p}_{t}$ is the $n_{2} \times 1$ vector of shadow prices associated with the nonpredetermined variables and the system is initialized with $\mathbf{x}_{0}$ known and $\mathbf{p}_{0}=\mathbf{0}$. These shadow prices are the direct analog to the Lagrange multipliers employed earlier, and they serve as state variables, keeping track of the current value of commitments, in the equilibrium (Kydland and Prescott, 1980).

\subsection{A timeless perspective solution}

With the solution to the optimal commitment problem in hand, the second step is to use these equilibrium relationships to derive an expression for the shadow prices. Importantly, since $\mathbf{d}_{t}$ 
contains all of the nonpredetermined variables and $\mathbf{A}_{\mathbf{y y}}$ has full rank, $\mathbf{G}_{\mathbf{d p}}$ is a $\left(n_{2}+p\right) \times n_{2}$ matrix with $\operatorname{rank}\left(\mathbf{G}_{\mathbf{d p}}\right)=n_{2}$. Rewriting equation (24) to make $\mathbf{p}_{t}$ the subject leads to

$$
\mathbf{p}_{t}=\mathbf{G}_{\mathbf{d p}}^{-1}\left(\mathbf{d}_{t}-\mathbf{G}_{\mathbf{d x}} \mathbf{x}_{t}\right)
$$

where $\mathbf{G}_{\mathbf{d p}}^{-1}$ represents the generalized (left) inverse of $\mathbf{G}_{\mathbf{d p}}$. The third step is to substitute equation (25) into equation (22) and into the lag of equation (23), thereby dispensing with the initial condition $\mathbf{p}_{0}=\mathbf{0}$. After some reorganization, the timeless perspective equilibrium can be written as

$$
\left[\begin{array}{c}
\mathbf{x}_{t+1} \\
\mathbf{x}_{t} \\
\mathbf{d}_{t}
\end{array}\right]=\left[\begin{array}{ccc}
\mathbf{M}_{\mathbf{x x}} & \mathbf{M}_{\mathbf{x p}}\left(\mathbf{M}_{\mathbf{p x}}-\mathbf{M}_{\mathbf{p} \mathbf{p}} \mathbf{G}_{\mathbf{d p}}^{-1} \mathbf{G}_{\mathbf{d x}}\right) & \mathbf{M}_{\mathbf{x p}} \mathbf{M}_{\mathbf{p p}} \mathbf{G}_{\mathbf{d p}}^{-1} \\
\mathbf{I} & \mathbf{0} & \mathbf{0} \\
\mathbf{G}_{\mathbf{d x}} & \mathbf{G}_{\mathbf{d p}}\left(\mathbf{M}_{\mathbf{p x}}-\mathbf{M}_{\mathbf{p p}} \mathbf{G}_{\mathbf{d} \mathbf{p}}^{-1} \mathbf{G}_{\mathbf{d x}}\right) & \mathbf{G}_{\mathbf{d p}} \mathbf{M}_{\mathbf{p} \mathbf{p}} \mathbf{G}_{\mathbf{d p}}^{-1}
\end{array}\right]\left[\begin{array}{c}
\mathbf{x}_{t} \\
\mathbf{x}_{t-1} \\
\mathbf{d}_{t-1}
\end{array}\right]+\left[\begin{array}{c}
\mathbf{I} \\
\mathbf{0} \\
\mathbf{0}
\end{array}\right]\left[\varepsilon_{t+1}\right]
$$

To understand why this procedure recovers correctly a timeless perspective equilibrium, consider the relationship between the optimal commitment problem and the timeless perspective problem. In both problems the policymaker has access to a mechanism that allows it to commit to its policy. The value of the central bank's policy commitments is encapsulated in shadow prices. Critically, aside from the initial period, the timeless perspective does not change either the constraints or the objectives in the optimization problem. As a consequence, the timeless perspective does not change the system's stability properties, nor does it change the system's eigenvalues or whether the shadow prices are predetermined, which is why the optimal commitment policy and the timeless perspective policy share the same asymptotic equilibrium. What the timeless perspective does change, however, is the system's initial conditions, which is why the optimal commitment policy and the timeless perspective policy have different period-0 transition dynamics and, with discounting, yield different losses.

But, although saddle-point solution methods require the partitioning between stable and unstable eigenvalues to conform to the partitioning between predetermined and nonpredetermined variables (both unaffected by the timeless perspective), they do not require an explicit declaration of the initial conditions. As a consequence, the timeless perspective equilibrium can be found by first applying standard rational expectations control methods. Once the equilibrium has been obtained for arbitrary initial conditions, the timeless perspective can be introduced by using the equilibrium relationships to solve for and subsequently eliminate the shadow prices. 


\subsubsection{Multiple representations of the timeless perspective solution}

It is well-known that timeless perspective policies are not unique. To see the multiplicity, note the role of the rank condition on $\mathbf{G}_{\mathbf{d p}}$. This rank condition ensures that the shadow prices obtained from equation (25) fully satisfy the model's equilibrium relationships. It follows that a valid solution for $\mathbf{p}_{t}$ can be obtained from any subset of the variables in $\mathbf{y}_{t}$ and $\mathbf{u}_{t}$ provided that the resulting $\mathbf{G}_{\mathbf{d p}}$ matrix has $\operatorname{rank}\left(\mathbf{G}_{\mathbf{d p}}\right)=n_{2}$. Although the particular state variables that enter the timeless perspective equilibrium will depend on which equilibrium relationships are used when solving for $\mathbf{p}_{t}$, by construction, they all imply the same welfare and equilibrium behavior. The fact that timeless perspective equilibria have multiple representations is also reflected in the fact that although the procedure described above yields an equilibrium in which $\mathbf{u}_{t}$ is a function of $\mathbf{x}_{t}, \mathbf{x}_{t-1}, \mathbf{y}_{t-1}$, and $\mathbf{u}_{t-1}$, the approach described in Section 2 would yield an equilibrium in which $\mathbf{u}_{t}$ is a function of $\mathbf{x}_{t}, \mathbf{y}_{t-1}, \mathbf{u}_{t-1}$, and $\mathbf{u}_{t-2} \cdot{ }^{9}$

\subsection{Evaluating policy performance}

For the general linear-quadratic control problem described by equations (19) through (21), the three policy approaches examined above have equilibria that can be written in the form

$$
\begin{aligned}
\mathbf{s}_{t+1} & =\mathbf{M}_{\mathbf{s s}} \mathbf{s}_{t}+\mathbf{N} \varepsilon_{t+1} \\
\mathbf{y}_{t} & =\mathbf{H}_{\mathbf{y s}} \mathbf{s}_{t} \\
\mathbf{u}_{t} & =\mathbf{F}_{\mathbf{u s}} \mathbf{s}_{t}
\end{aligned}
$$

where $\mathbf{s}_{t} \equiv\left[\begin{array}{ll}\mathbf{x}_{t}^{\prime} & \mathbf{q}_{t}^{\prime}\end{array}\right]^{\prime}$. For the discretionary policy $\mathbf{q}_{t}$ is the null vector, for the optimal commitment policy $\mathbf{q}_{t}=\mathbf{p}_{t}$, and for the timeless perspective policy $\mathbf{q}_{t}=\left[\begin{array}{ll}\mathbf{x}_{t-1}^{\prime} & \mathbf{d}_{t-1}^{\prime}\end{array}\right]^{\prime}$. Now, as Currie and Levine (1993) show in the continuous-time context, for arbitrary period $t$, equations (27) through (29) allow the loss function, conditional on $\mathbf{s}_{t}$, to be expressed as

$$
L_{t}=\mathbf{s}_{t}^{\prime} \mathbf{P} \mathbf{s}_{t}+\frac{\beta}{1-\beta} \operatorname{tr}\left(\mathbf{N}^{\prime} \mathbf{P} \mathbf{N} \mathbf{\Sigma}\right)
$$

where

$$
\begin{aligned}
\mathbf{P} & =\widehat{\mathbf{W}}+\beta \mathbf{M}_{\mathrm{ss}}^{\prime} \mathbf{P} \mathbf{M}_{\mathrm{ss}} \\
\widehat{\mathbf{W}} & \equiv \mathbf{H}_{\mathrm{ys}}^{\prime} \mathbf{W} \mathbf{H}_{\mathbf{y s}}+\mathbf{H}_{\mathbf{y s}}^{\prime} \mathbf{U F}_{\mathbf{u s}}+\mathbf{F}_{\mathrm{us}}^{\prime} \mathbf{U}^{\prime} \mathbf{H}_{\mathrm{ys}}+\mathbf{F}_{\mathrm{us}}^{\prime} \mathbf{R} \mathbf{F}_{\mathbf{u s}}
\end{aligned}
$$

\footnotetext{
${ }^{9}$ Importantly, this well-known multiplicity of representations makes no material difference for the analysis or conclusions that follow, since it is assumed - for consistency - that the conditioning variables satisfy the timeless perspective equilibrium relationships.
} 
In light of equation (30), unconditional loss is given by

$$
\begin{aligned}
\bar{L} & =\int_{\mathbf{s}}\left[\mathbf{s}_{t}^{\prime} \mathbf{P} \mathbf{s}_{t}+\frac{\beta}{1-\beta} \operatorname{tr}\left(\mathbf{N}^{\prime} \mathbf{P} \mathbf{N} \boldsymbol{\Sigma}\right)\right] p\left(\mathbf{s}_{t}\right) d \mathbf{s}_{t} \\
& =\operatorname{tr}(\mathbf{P} \boldsymbol{\Omega})+\frac{\beta}{1-\beta} \operatorname{tr}\left(\mathbf{N}^{\prime} \mathbf{P} \mathbf{N} \boldsymbol{\Sigma}\right)
\end{aligned}
$$

where $p\left(\mathbf{s}_{t}\right)$ denotes the density function for $\mathbf{s}_{t}$ and $\boldsymbol{\Omega}$ represents the unconditional variance of $\mathbf{s}_{t}$.

The performances shown in Figure $1 \mathrm{~A}$ were calculated using $(1-\beta) L_{t}$, while those in Figure 1B were calculated using $(1-\beta) \bar{L}$. However, recognizing the deficiencies of these two performance measures, rather than assert initial values for the auxiliary states, as equation (30) does, and rather than integrate with respect to the entire state, $\mathbf{s}_{t}$, as equation (33) does, I propose to integrate with respect to $\mathbf{q}_{t}$ conditional on $\mathbf{x}_{t}$, and to evaluate the performance of timeless perspective policies according to

$$
\widehat{L}_{t}=\int_{\mathbf{q}}\left[\mathbf{s}_{t}^{\prime} \mathbf{P} \mathbf{s}_{t}+\frac{\beta}{1-\beta} \operatorname{tr}\left(\mathbf{N}^{\prime} \mathbf{P N} \boldsymbol{\Sigma}\right)\right] p\left(\mathbf{q}_{t} \mid \mathbf{x}_{t}\right) d \mathbf{q}_{t},
$$

where $p\left(\mathbf{q}_{t} \mid \mathbf{x}_{t}\right)$ denotes the density function for $\mathbf{q}_{t}$ conditional on $\mathbf{x}_{t}$. To evaluate this integral, partition $\boldsymbol{\Omega}$ (and subsequently $\mathbf{M}_{\mathbf{s s}}$ and $\mathbf{P}$ ) conformably with $\mathbf{x}_{t}$ and $\mathbf{q}_{t}$, then the mean and variance of $\mathbf{q}_{t}$ conditional on $\mathbf{x}_{t}$, are given by

$$
\begin{aligned}
\overline{\mathbf{q}}_{t} & =\boldsymbol{\Omega}_{\mathbf{q x}} \boldsymbol{\Omega}_{\mathbf{x x}}^{-1} \mathbf{x}_{t} \\
\boldsymbol{\Omega}_{\mathbf{q}_{t} \mid \mathbf{x}_{t}} & =\boldsymbol{\Omega}_{\mathbf{q q}}-\boldsymbol{\Omega}_{\mathbf{q x}} \boldsymbol{\Omega}_{\mathbf{x x}}^{-1} \boldsymbol{\Omega}_{\mathbf{x q}}
\end{aligned}
$$

and equation (34) is equivalent to

$$
\widehat{L}_{t}=\mathbf{x}_{t}^{\prime}\left(\mathbf{P}_{\mathbf{x x}}+\mathbf{P}_{\mathbf{x q}} \boldsymbol{\Omega}_{\mathbf{q} \mathbf{x}} \boldsymbol{\Omega}_{\mathbf{x x}}^{-1}+\boldsymbol{\Omega}_{\mathbf{x x}}^{-1^{\prime}} \boldsymbol{\Omega}_{\mathbf{q} \mathbf{x}}^{\prime} \mathbf{P}_{\mathbf{q x}}\right) \mathbf{x}_{t}+\operatorname{tr}\left(\mathbf{P}_{\mathbf{q q}} \boldsymbol{\Omega}_{\mathbf{q} t \mid \mathbf{x}_{t}}\right)+\frac{\beta}{1-\beta} \operatorname{tr}\left(\mathbf{N}^{\prime} \mathbf{P N} \boldsymbol{\Sigma}\right) .
$$

Equation (37) contains three terms. The first and third terms represent the penalties attributable to the known initial state and to the stochastic shocks, respectively. The second term represents the penalty associated with the conditional variance of the auxiliary states that are introduced by timeless perspective policymaking. By integrating out the auxiliary state variables, equation (37) measures average loss for a given state, $\mathbf{x}_{t}$. In the absence of any auxiliary states, equation (37) is equivalent to equation (30). Further, in the limit as $\beta \uparrow 1$, equations (37) and (33), each scaled by $(1-\beta)$, converge.

Before leaving this section, it is worth noting that policy performance, as assessed by equation (37), is invariant to how the timeless perspective equilibrium is represented, unaffected 
by the particular choice of $\mathbf{d}_{t}$ or by the fact that $\mathbf{G}_{\mathbf{d p}}^{-1}$ may not be unique. To understand why, note that the substantive difference between the optimal commitment equilibrium and the timeless perspective equilibrium is that the shadow prices, $\mathbf{p}_{t}$, are not initialized to $\mathbf{0}$, but rather behave in the initial period as they do in all subsequent periods. It follows that there is actually no need to eliminate the shadow prices from the system (the step that leads to multiple representations) when evaluating equation (37). Instead, one can simply integrate with respect to the shadow prices conditional on $\mathbf{x}_{t}$. Because the optimal commitment policy has a unique representation in terms of $\mathbf{x}_{t}$ and $\mathbf{p}_{t}$ (under standard and quite general conditions), so too does the timeless perspective equilibrium, and this unique representation yields unique values for the mean and variance of $\mathbf{p}_{t}$ conditional on $\mathbf{x}_{t} \cdot{ }^{10}$

\section{Two examples}

In this section two New Keynesian models, each reflective of those employed in the monetary policy literature, are analyzed to assess whether and when discretionary policy is superior to timeless perspective policy. For this exercise, policy performance is measured by equation (37). The first model is the simple New Keynesian model introduced for expository purposes in Section 2.1. The second model is a medium-scale DSGE model in the style of Christiano, Eichenbaum, and Evans (2005), Smets and Wouters (2003), and Levin, Onatski, Williams, and Williams (2006). The results from this second model are particularly interesting because it is highly representative of the workhorse models routinely used for monetary, and much business cycle, analysis. In each model, policy performance is evaluated under discretion and the timeless perspective and, for a wide range of parameter values, the results indicate that discretion can be superior to the timeless perspective.

\subsection{Results for the simple New Keynesian model}

To analyze the simple New Keynesian model policy performance is evaluated according to $(1-\beta) \widehat{L}_{t}=(1-\beta) E_{q \mid x}\left(L_{t}\right)$ while varying $\kappa$, the slope of the Phillips curve, and $\mu$, the weight on gap stabilization. ${ }^{11}$ Figure $2 \mathrm{~A}$ displays the performances for the optimal commitment policy, the timeless perspective policy, and the time-consistent policy as $\kappa$ is varied between

\footnotetext{
${ }^{10}$ Without wishing to labor the point, this invariance property is also a feature of unconditional loss, and for the same reason. Unconditional loss is invariant to the multiplicity of representations because it integrates out the entire state vector, which includes the auxillary states.

${ }^{11}$ Consistent with Figure 1, the benchmark parameterization has $\kappa=0.025, \mu=0.50, \rho_{u}=0.20$, and $\sigma_{\epsilon_{u}}=1$, and the initial state given by $u_{0}=0$.
} 
$(0,0.1]$, holding $\rho_{u}, \mu$, and $\sigma_{\epsilon_{u}}$ constant at their benchmark values. Complementing Figure 2A, Figure $2 \mathrm{C}$ displays the performances associated with varying $\mu$ between $(0,10]$ while holding $\rho_{u}, \kappa$, and $\sigma_{\epsilon_{u}}$ constant at their benchmark values. In contrast, Figures $2 \mathrm{~B}$ and $2 \mathrm{D}$ are generated allowing both $\kappa$ and $\mu$ to vary between $(0,0.1]$ and $(0,10]$, respectively, displaying as a percent the fraction of occasions for which the discretionary policy performs better than the timeless perspective policy against particular values of $\kappa$ and $\mu$, respectively.

\section{[ Figure 2 here ]}

Figure $2 \mathrm{~A}$ reveals that, ceteris paribus, discretion performs better than timeless perspective policymaking when $\kappa$ is small and the Phillips curve is relatively flat. Low values for $\kappa$ can arise when prices adjust infrequently and/or when strategic complementarities are important. When the Phillips curve is relatively flat, monetary policy must generate large movements in the output gap to stabilize inflation, and, relative to discretion, these large movements in the output gap undermine the performance of the timeless perspective policy. Similarly, ceteris paribus, Figure 2C shows that discretion does better than timeless perspective policymaking when $\mu$ is large. Complementing these findings, Figure $2 \mathrm{~B}$ shows that, although the share of the parameter space for which discretion dominates the timeless perspective is decreasing in $\kappa$, there appears to be a threshold value for $\kappa$ above which timeless perspective policymaking always dominates. Figure 2D reveals that the share of the parameter space for which discretion dominates timeless perspective policymaking increases monotonically with the weight on output gap stabilization.

Importantly, for this model, and with $\mu$ chosen appropriately, the quadratic loss function that underpins the performance calculation is equivalent to a second-order approximation to household utility. Although the weight on the output gap in the approximated utility function is typically small, panel $\mathrm{D}$ shows that discretion can dominate the timeless perspective even when $\mu$ is small, provided the Phillips curve is sufficiently flat. The main conclusion to take away from Figure 2 are that, although the improvement in policy performance may be small, discretion is more likely to perform better than timeless perspective policymaking when the Phillips curve is relatively flat and when the weight on output gap stabilization is relatively large. 


\subsection{Results for a medium-scale DSGE model}

Having shown that discretion can be superior to the timeless perspective in the simple New Keynesian model, I now undertake a broader analysis using a more sophisticated business cycle model that contains a wider array of shocks, rigidities, and propagation mechanisms. Importantly, as with the simple model, the results indicate that discretion can be superior to timeless perspective policymaking.

In this model, a unit-continuum of monopolistically competitive firms use capital and labor to produce according to a constant-returns Cobb-Douglas production function. These firms set prices to maximize the expected discounted value of the firm, subject to a Calvo (1983) price rigidity and, following Smets and Wouters (2003), firms that cannot change their price in a given period are assumed to index their price to lagged aggregate inflation. The goods produced by these firms are then aggregated according to a Kimball (1995) technology to produce an aggregate final good that is sold in a perfectly competitive market to households for consumption purposes and to firms for investment purposes. Investment goods purchased by firms are combined with existing capital to produce new capital, as per Woodford (2005).

Households are monopolistic suppliers of their labor. They choose their consumption, nominal wage, and holdings of one-period nominal bonds to maximize their expected discounted lifetime utility. Following on Erceg, Henderson, and Levin (2000), households set their wage subject to a Calvo-style wage rigidity, with those households unable to change their wage assumed to index their wage to lagged aggregate inflation (Rabanal and Rubio-Ramírez, 2005). With respect to monetary policy, I assume, for simplicity, that the central bank's decision problem is to choose the interest rate on a one-period nominal bond to optimize the expected discounted value of a quadratic loss function defined over inflation and the output gap, where the expectation is conditional on period- $t$ information. Appendix A provides the complete log-linear specification of the model.

As earlier, policy performance is analyzed on a parameter grid. The results are shown in Figure 3, which displays, for key parameters, the share of the parameter space for which discretion is the superior policy.

[ Figure 3 here ]

Figure 3 illustrates that the performance of discretion relative to timeless perspective policymaking increases as price rigidity, $\xi_{p}$, wage rigidity, $\xi_{w}$, Kimball curvature, $\omega$, the labor substitution elasticity, $\phi$, and the output stabilization weight, $\mu$, increase and declines as 
price indexation, $\iota_{p}$, wage indexation, $\iota_{w}$, and the goods substitution elasticity, $\varepsilon$, increase. ${ }^{12}$ Since higher values of $\xi_{p}$ imply a flatter price Phillips curve and higher values of $\xi_{w}$ imply a flatter wage Phillips curve, the results in Figure 3A and Figure 3C are consistent with those in Figure 2A. Similarly, higher values of $\omega$ also serve to flatten the price Phillips curve and higher values of $\phi$ serve to flatten the wage Phillips curve, explaining why the relative performance of discretion improves as these parameter increase (Figures $3 \mathrm{E}$ and $3 \mathrm{G}$, respectively). With respect to $\mu$, the result in Figure $3 \mathrm{H}$ is also consistent with the simple New Keynesian model. With respect to $\iota_{p}, \iota_{w}$, and $\varepsilon$, whether increases in these parameters help or hinder discretion turns primarily on how they alter the trade-off the central bank faces between stabilizing inflation and stabilizing the output gap. With respect to $\varepsilon$, higher values can help discretion because they lower the steady-state consumption share of output, weakening the policy channel operating on real marginal costs through consumption and wages. However, with the Kimball (1995) aggregator, higher values of $\varepsilon$ also steepen the slope of the price Phillips curve, which hinders discretion. In this model, on balance, the latter effect dominates. Higher values of $\iota_{p}$ and $\iota_{w}$ worsen the relative performance of discretion because these indexation parameters raise the importance of being able to manage price-sector expectations in order to prevent adverse shocks from having enduring effects on price and wage inflation.

\section{Conclusion}

This paper shows that discretion can be superior to timeless perspective policymaking and identifies factors that contribute to this outcome occurring. Broadly speaking, discretion is more likely to be superior to timeless perspective policymaking when the Phillips curve is relatively flat, i.e., in models where nominal price rigidity is important and/or where factors such as Kimball aggregation or firm-specific labor/capital are present. These findings are important because these very factors are becoming widely employed in the New Keynesian DSGE models used to analyze monetary policy. Although a timeless perspective approach to policymaking has its attractions, one cannot simply assume that timeless perspective policymaking

\footnotetext{
${ }^{12}$ In addition to these parameter, the model contains parameters for the depreciation rate on capital, $\delta$, the production coefficient on capital, $\alpha$, the Frisch labor supply elasticity, $\chi$, the elasticity of intertemporal substitution, $\sigma^{-1}$, and the capital adjustment cost, $\eta$. However, to keep the exercise manageable, $\delta, \alpha, \chi, \eta$, and $\sigma$, and the parameters in the shock processes are held constant since preliminary investigations indicated these parameters were largely unimportant for the results. Based on the estimates in Levin, Onatski, Williams, and Williams, (2006) and Smets and Wouters (2007), the model is parameterized by setting $\beta=0.99, \delta=0.025$, $\alpha=0.36, \sigma=2.19, \chi=1.49$, and $\eta=5.74$. In addition, the shock processes are parameterized according to $\rho_{g}=\rho_{v}=0.3$ and $\rho_{u}=0.95$. Lastly, the initial state is parameterized on the assumption that the economy initially resides at its nonstochastic steady state.
} 
is superior to discretion.

One difficulty with comparing discretion to timeless perspective policymaking has been finding a suitable metric for assessing performance. This difficulty arises because the timeless perspective introduces auxiliary state variables that are absent from the discretionary equilibrium. Rather than simply assigning initial values to these auxiliary state variables or using unconditional loss to evaluate policies, this paper proposes to evaluate policies using a measure of conditional loss that integrates out the auxiliary state variables conditional upon the known predetermined state variables. The resulting measure of policy performance is easy to compute, provides a consistent treatment of the initial conditions in the discretion and the timeless perspective equilibria, and is consistent with the conditioning assumptions that describe the associated optimization problems.

The goal of this paper has not been to criticize the timeless perspective as an approach to policy design. Rather, because timeless perspective policies are suboptimal, the goal has been to highlight that timeless perspective policies are not necessarily superior to other suboptimal policies, of which discretion is a leading example. Afterall, it is unclear why a central bank should commit to implementing a timeless perspective policy when that policy is inferior to a time consistent alternative. The results in this paper suggest that studies analyzing timeless perspective policies might usefully consider their performance alongside that of discretion, evaluating the policies using the measure of policy performance developed in this paper.

\section{References}

[1] Backus, D., Driffill, J., 1986. The Consistency of Optimal Policy in Stochastic Rational Expectations Models. Centre for Economic Policy Research Discussion Paper \#124.

[2] Benigno, P., and Woodford, M., 2003. Optimal Monetary and Fiscal Policy: A LinearQuadratic Approach. In: Gertler, M., and Rogoff, K., (eds), NBER Macroeconomics Annual 2003. MIT Press, Cambridge.

[3] Benigno, P., and Woodford, M., 2006. Linear-Quadratic Approximation of Optimal Policy Problems. NBER Working Paper \#12672, (version dated August 4, 2008).

[4] Blake, A., 2001. A 'Timeless Perspective' on Optimality in Forward-Looking Rational Expectations Models. National Institute of Economic and Social Research Working Paper \#188 (version dated October 11, 2001).

[5] Calvo, G., 1983. Staggered Contracts in a Utility-Maximising Framework. Journal of Monetary Economics 12, 383-398.

[6] Christiano, L., Eichenbaum, M., and Evans, C., 2005. Nominal Rigidities and the Dynamic Effects of a Shock to Monetary Policy. Journal of Political Economy 113, 1-45.

[7] Cohen, D., and Michel, P., 1988. How Should Control Theory be Used to Calculate a Time-Consistent Government Policy? Review of Economic Studies 55, 263-274. 
[8] Currie, D., and Levine, P., 1993. Rules, Reputation and Macroeconomic Policy Coordination, Cambridge University Press, Cambridge.

[9] Damjanovic, T., Damjanovic, V., and Nolan, C., 2008. Unconditionally Optimal Monetary Policy. Journal of Monetary Economics 55, 491-500.

[10] Debartoli, D., and Nunes, R., 2006. Fiscal Policy under Loose Commitment. Journal of Economic Theory, forthcoming, (version dated September 10, 2009).

[11] Erceg, C., Henderson, D., and Levin, A., 2000. Optimal Monetary Policy with Staggered Wage and Price Contracts. Journal of Monetary Economics 46, 281-313.

[12] Giannoni, M., and Woodford, M., 2002a. Optimal Interest-Rate Rules: I. General Theory. NBER Working Paper \#9419, (version dated December 16, 2002).

[13] Giannoni, M., and Woodford, M., 2002b. Optimal Interest-Rate Rules: II. Applications. NBER Working Paper \#9420, (version dated December 16, 2002).

[14] Giannoni, M., and Woodford, M., 2009. Optimal Target Criteria for Stabilization Policy. manuscript, (version dated October 2, 2009).

[15] Jensen, C., and McCallum, B., 2002. The Non-Optimality of Proposed Monetary Policy Rules Under Timeless Perspective Commitment. Economics Letters 77, 163-168.

[16] Khan, A., King, R., and Wolman, A., 2003. Optimal Monetary Policy. Review of Economic Studies 70, 825-860.

[17] King, R., and Wolman, A., 1999. What Should the Monetary Authority Do When Prices are Sticky? In: Taylor, J., (ed), Monetary Policy Rules. University of Chicago Press, Chicago, pp. 349-396.

[18] Kim, J., Kim, S., Schaumburg, E., and Sims, C., 2008. Calculating and Using Second Order Accurate Solutions of Discrete Time Dynamic Equilibrium Models. Journal of Economic Dynamics and Control 32, 3397-3414.

[19] Kimball, M., 1995. The Quantitative Analytics of the Basic Neomonetarist Model. Journal of Money, Credit, and Banking 27, 1241-1277.

[20] Kydland, F., and Prescott, E., 1977. Rules Rather Than Discretion: The Inconsistency of Optimal Plans. Journal of Political Economy 87, 473-492.

[21] Kydland, F., and Prescott, E., 1980. Dynamic Optimal Taxation, Rational Expectations and Optimal Control. Journal of Economic Dynamics and Control 2, 79-91.

[22] Levin, A., Onatski, A., Williams, J., and Williams, N., 2006. Monetary Policy Under Uncertainty in Micro-Founded Macroeconometric Models. In: Gertler, M., and Rogoff, K., (eds), NBER Macroeconomics Annual 2005. MIT Press, Cambridge, Massachusetts, 229-287.

[23] McCallum, B., and Nelson, E., 2004. Timeless Perspective vs. Discretionary Monetary Policy in Forward-Looking Models. Federal Reserve Bank of St. Louis Economic Review, March/April, 43-56.

[24] Oudiz, G., and Sachs, J., 1985. International Policy Coordination in Dynamic Macroeconomic Models. In: Buiter, W., and Marston, R., (eds), International Economic Policy Coordination. Cambridge University Press, Cambridge, 275-319.

[25] Rabanal, P., and Rubio-Ramírez, J., 2005. Comparing New Keynesian Models of the Business Cycle: A Bayesian Approach. Journal of Monetary Economics 52, 1151-1166. 
[26] Sauer, S., 2007. Discretion Rather than Rules? When is Discretionary Policy-Making Better than the Timeless Perspective? European Central Bank Working Paper \#717 (version dated January 23, 2007).

[27] Schaumburg, E., and Tambalotti, A., 2007. An Investigation of the Gains from Commitment in Monetary Policy. Journal of Monetary Economics 54, 302-324.

[28] Smets, F., and Wouters, R., 2003. An Estimated Dynamic Stochastic General Equilibrium Model of the Euro Area. Journal of the European Economic Association 1, 1123-1175.

[29] Smets, F., and Wouters, R., 2007. Shocks and Frictions in US Business Cycles: A Bayesian DSGE Approach. American Economic Review 97, 586-606.

[30] Söderlind, P., 1999. Solution and Estimation of RE Macromodels with Optimal Policy. European Economic Review 43, 813-823.

[31] Walsh, C., 2003. Speed Limit Policies: The Output Gap and Optimal Monetary Policies. American Economic Review 93, 265-278.

[32] Woodford, M., 1999a. Commentary: How Should Monetary Policy Be Conducted in an Era of Price Stability? In: Federal Reserve Bank of Kansas City (ed), New Challenges for Monetary Policy, Kansas City.

[33] Woodford, M., 1999b. Optimal Monetary Policy Inertia. The Manchester School Supplement 67 , supplement, 1-35.

[34] Woodford, M., 2003. Interest and Prices: Foundations of a Theory of Monetary Policy. Princeton University Press, Princeton, New Jersey.

[35] Woodford, M., 2005. Inflation and Output Dynamics with Firm-Specific Investment. International Journal of Central Banking 1, 1-46.

\section{Appendix}

The constraints and first-order conditions for the medium-scale DSGE model analyzed in section 4.2 are

$$
\begin{aligned}
\pi_{t} & =\frac{\iota_{p}}{1+\beta \iota_{p}} \pi_{t-1}+\frac{\beta}{1+\beta \iota_{p}} \mathrm{E}_{t} \pi_{t+1}+\frac{\left(1-\xi_{p}\right)\left(1-\beta \xi_{p}\right)}{\xi_{p}\left(1+\beta \iota_{p}\right)} \frac{(\varepsilon-1)}{(\varepsilon+\omega-1)} m c_{t}+v_{t} \\
m c_{t} & =w_{t}-p_{t}-y_{t}+l_{t} \\
\Delta w_{t} & =\iota_{w} \pi_{t-1}+\beta \mathrm{E}_{t} \Delta w_{t+1}-\iota_{w} \beta \pi_{t}+\frac{\left(1-\xi_{w}\right)\left(1-\beta \xi_{w}\right)}{\xi_{w}(1+\chi \phi)}\left(m r s_{t}-w_{t}+p_{t}\right) \\
m r s_{t} & =\chi l_{t}+\sigma c_{t}-g_{t} \\
w_{t}-p_{t} & =w_{t-1}-p_{t-1}+\Delta w_{t}-\pi_{t} \\
c_{t} & =\mathrm{E}_{t} c_{t+1}-\frac{1}{\sigma}\left(r_{t}-\mathrm{E}_{t} \pi_{t+1}-g_{t}+\mathrm{E}_{t} g_{t+1}\right) \\
k_{t+1} & =\frac{1}{1+\beta} k_{t}+\frac{\beta}{1+\beta} \mathrm{E}_{t} k_{t+2}+\frac{1-\beta(1-\delta)}{(1+\beta) \eta} \mathrm{E}_{t} m s_{t+1}-\frac{1}{(1+\beta) \eta}\left(r_{t}-\mathrm{E}_{t} \pi_{t+1}\right)(44) \\
m s_{t} & =w_{t}-p_{t}-k_{t}+l_{t} \\
y_{t} & =u_{t}+\alpha k_{t}+(1-\alpha) l_{t} \\
y_{t} & =(1-\gamma) c_{t}+\frac{\gamma}{\delta}\left[k_{t+1}-(1-\delta) k_{t}\right]
\end{aligned}
$$


Equation (38) is a hybrid New Keynesian Phillips curve linking inflation, $\pi_{t}$, to movements in real marginal costs, $m c_{t}$. In this Phillips curve, $\beta \in(0,1)$ is the subjective discount factor, $\iota_{p} \in[0,1)$ is the indexation parameter, $\xi_{p} \in(0,1)$ is the Calvo price-rigidity parameter, $\varepsilon \in(1, \infty)$ is the steady-state elasticity of substitution among goods, and $\omega \in[0, \infty)$ is the Kimball curvature parameter, the price elasticity of $\varepsilon$. With $w_{t}$ representing the nominal wage, $p_{t}$ representing the aggregate price level, $l_{t}$ representing aggregate labor, and $y_{t}$ representing aggregate output, equation (39) documents the relationship between real marginal costs and labor's share of income. Equation (40) is a wage Phillips curve, whose driving variable is the deviation of the marginal rate of substitution between consumption and leisure, $m r s_{t}$, from the real wage. In this wage Phillips curve, $\iota_{w} \in[0,1)$ is the indexation parameter, $\xi_{w} \in(0,1)$ is the Calvo wage-rigidity parameter, $\chi \in(0, \infty)$ is the Frisch labor supply elasticity, and $\phi \in(1, \infty)$ is the elasticity of substitution among labor-types.

The marginal rate of substitution between consumption, $c_{t}$, and leisure is summarized by equation (41), in which $\sigma^{-1} \in(0, \infty)$ represents the elasticity of intertemporal substitution. Equation (43) is the standard consumption-Euler equation for time-separable isoelastic preferences. Equation (44), written in terms of aggregate capital, $k_{t}$, represents the (aggregated) Euler equation for investment, which depends, in part, on the relationship between the average marginal return on capital, $m s_{t}$, and the expected real return on the one-period nominal bond, $r_{t}-\mathrm{E}_{t} \pi_{t+1}$. In this equation, $\delta \in(0,1)$ is the depreciation rate and $\eta \in(0, \infty)$ is the elasticity of the investment-to-capital ratio with respect to Tobin's q evaluated at steady state. Equation (45) summarizes firms' aggregate demand for labor, equation (46), is the production function, and equation (47) is the aggregate resource constraint. In the production function and the resource constraint, $\alpha \in(0,1)$ is the Cobb-Douglas production parameter and $\gamma \equiv \frac{\alpha \delta}{\rho+\delta} \frac{\varepsilon-1}{\varepsilon}$, where $\rho \equiv \frac{1-\beta}{\beta}$ is the discount rate, is the steady-state share of investment in output.

Completing the model specification, the markup shock, $v_{t}$, the consumption preference shock, $g_{t}$, and the aggregate technology shock, $u_{t}$, are assumed to evolve over time according to

$$
\begin{aligned}
v_{t+1} & =\rho_{v} v_{t}+\epsilon_{v t+1}, \\
g_{t+1} & =\rho_{g} g_{t}+\epsilon_{g t+1}, \\
u_{t+1} & =\rho_{u} u_{t}+\epsilon_{u t+1},
\end{aligned}
$$

where $\left\{\rho_{v}, \rho_{g}, \rho_{u}\right\} \in(-1,1)$, and where the innovations $\left\{\epsilon_{v_{t+1}}, \epsilon_{g_{t+1}}, \epsilon_{u_{t+1}}\right\}$ are i.i.d. with zero mean and finite variance.

Turning now to monetary policy, the central bank's decision problem is to choose $\left\{r_{t}\right\}_{0}^{\infty}$ to optimize the primal loss function

$$
\mathrm{E}_{0} \sum_{t=0}^{\infty} \beta^{t}\left(\pi_{t}^{2}+\mu y_{t}^{2}\right),
$$

subject to equations (38) through (50) and the known initial conditions $v_{0}, g_{0}, u_{0}$, and $k_{0}$. 
A: Loss

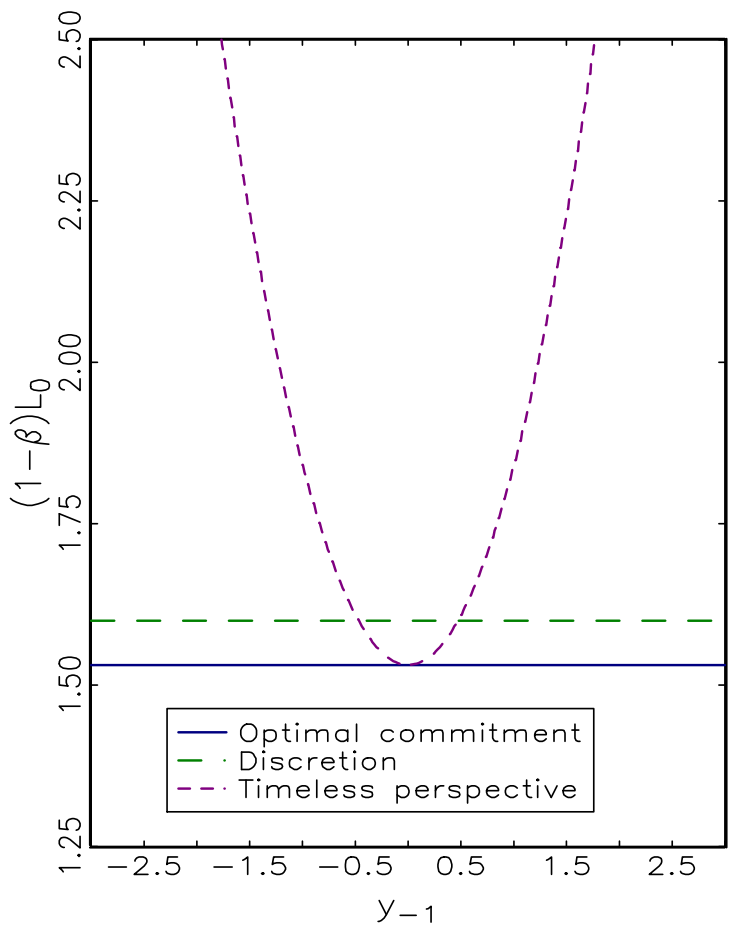

B: Unconditional Loss

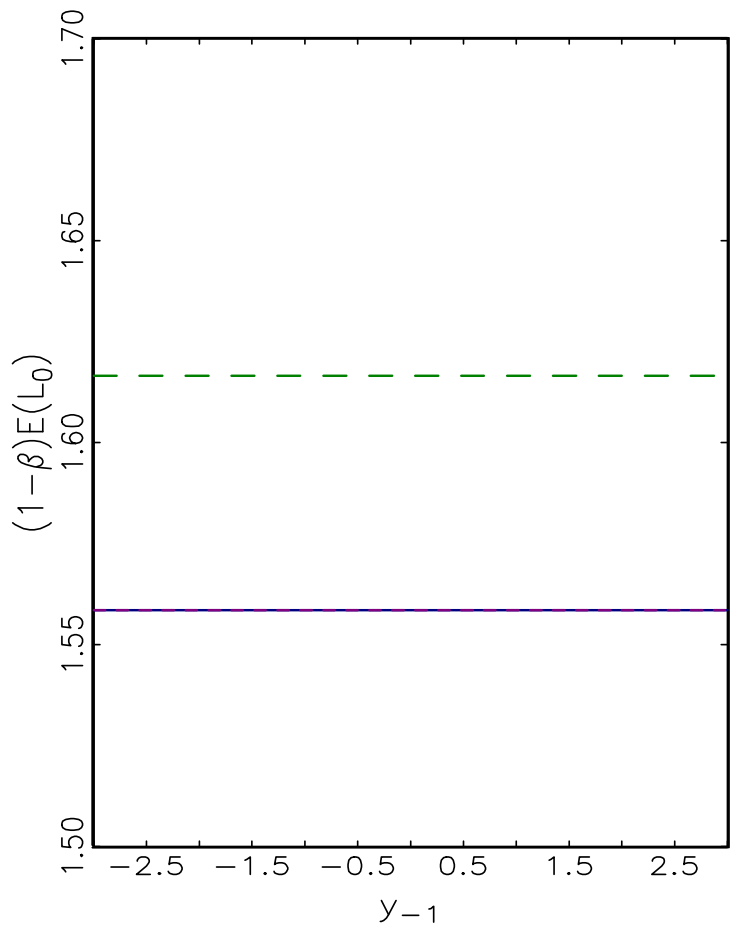

Figure 1: Two standard measures of policy performance.

Note: Panel A displays Loss under optimal commitment, timeless perspective commitment, and discretion for different values of the auxiliary state variable. Panel B complements panel A, but uses unconditional loss to measure policy performance. 
A: Policy Performance
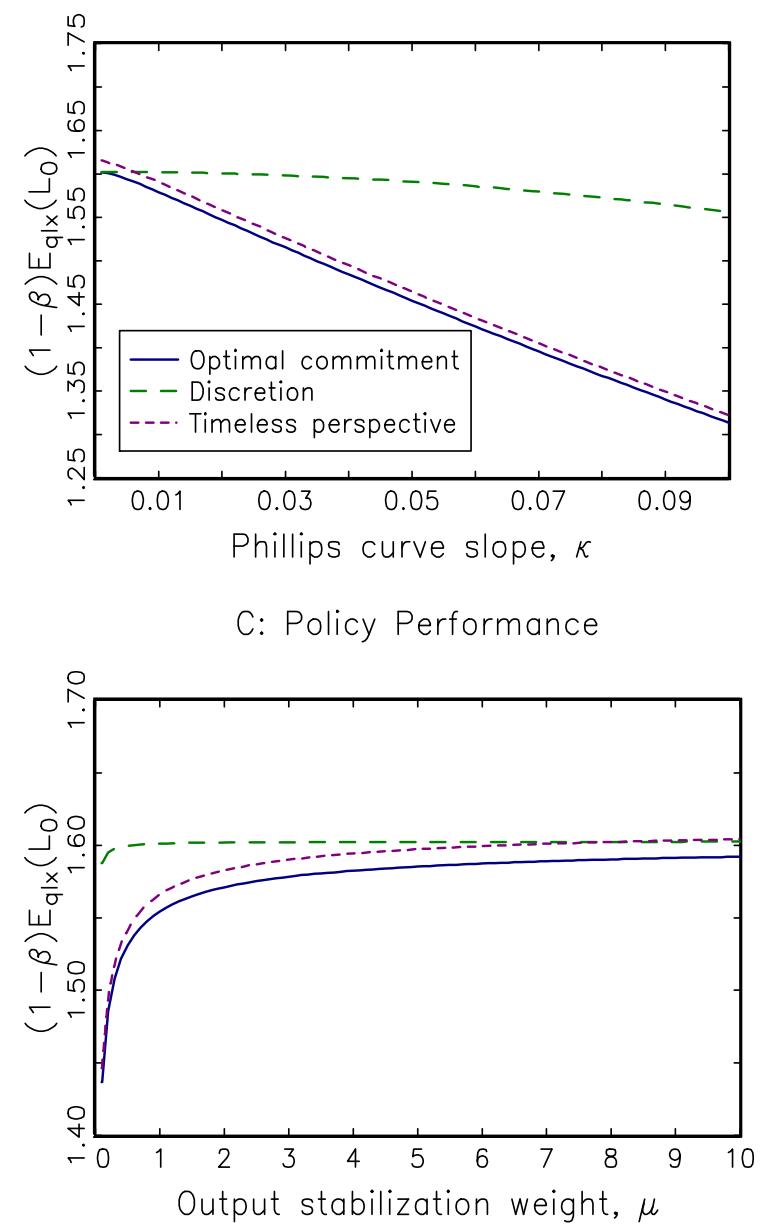

B: Discretion dominates timeless

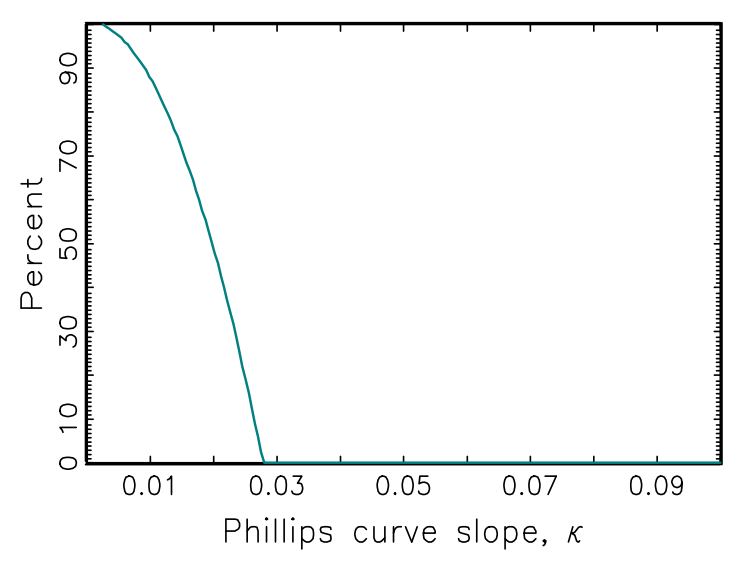

D: Discretion dominates timeless

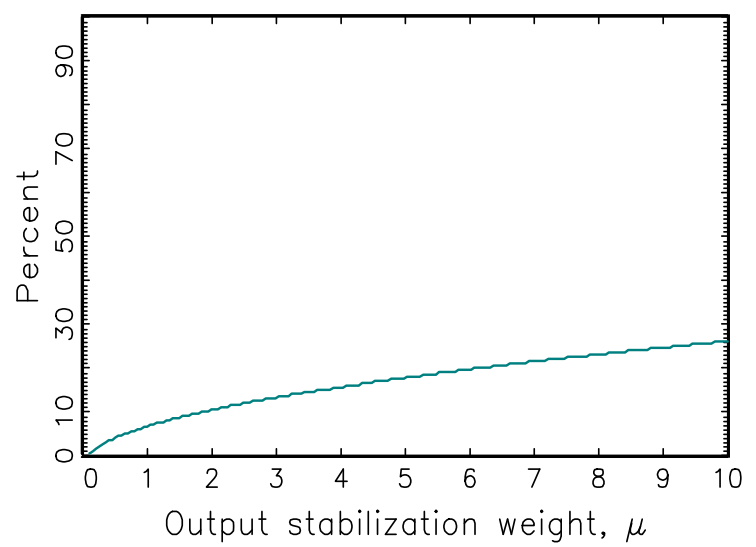

Figure 2: Policy performance in the simple New Keynesian model.

Note: Panels $\mathrm{A}$ and $\mathrm{C}$ display policy performance under timeless perspective policymaking and discretion as $\kappa$ and $\mu$, respectively, are varied, holding all other parameters constant. Panels B and D allows both $\kappa$ and $\mu$ to vary and display as a percent the occasions for which discretion performs better than the timeless perspective against particular values for $\kappa$ (panel B) and $\mu$ (panel D). 
A

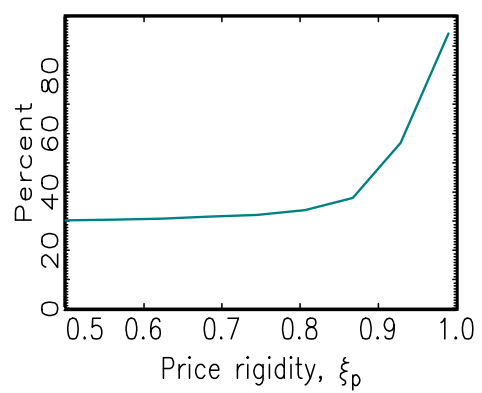

D

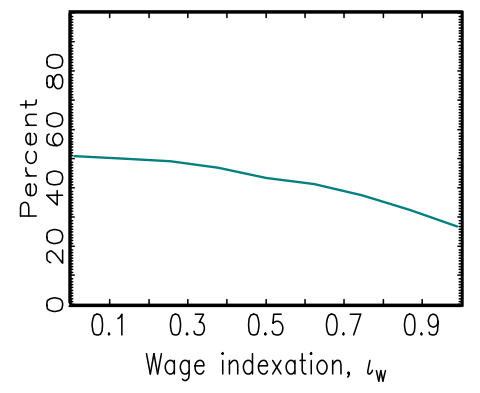

G

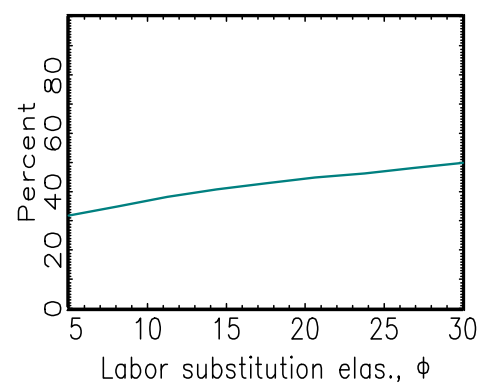

B

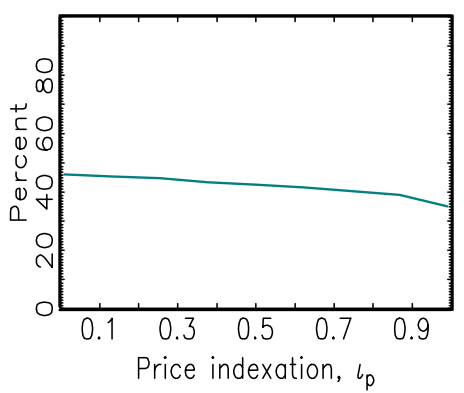

$E$

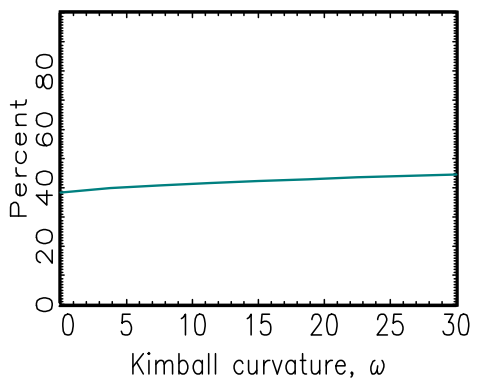

H

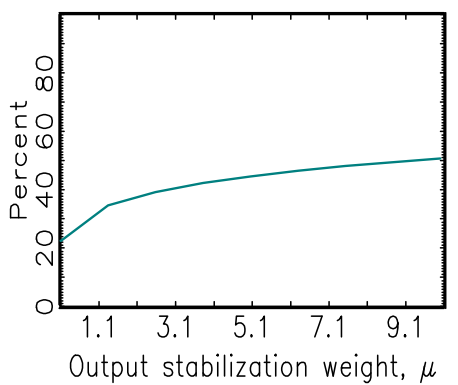

C

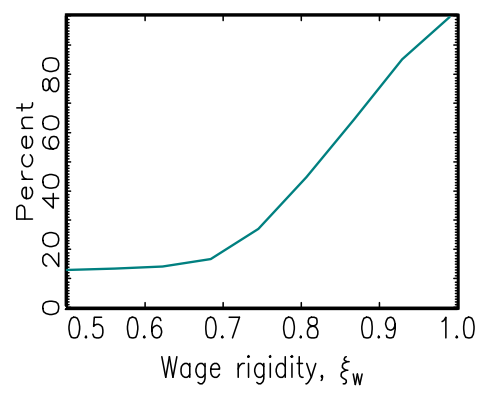

$\mathrm{F}$

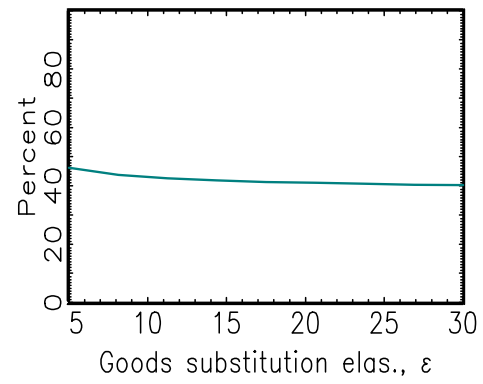

Figure 3: Policy performance in the medium-scale DSGE model.

Note: The panels in this figure display as a percent the occasions for which discretion performs better than the timeless perspective against particular values of key model parameters. 